\section{Coming Events}

\section{0}

APMC-2020 - 12th Asia-Pacific Microscopy Conference

February 3-7, 2020

Hyderabad, India

www.apmc12.in

Biophysical Society 64th Annual Meeting

February 15-19, 2020

San Diego, CA

www.biophysics.org/Meetings/AnnualMeeting/

FutureAnnualMeetings/tabid/495/Default.aspx

ACMM 26 - 26th Australian Conference on Microscopy and Microanalysis

February 16-20, 2020

Canberra, Australia

www.acmm26.org/welcome

United States and Canadian Academy of Pathology (USCAP) Annual Meeting 2020

February 29-March 5, 2020

Los Angeles, CA

www.uscap.org/uscap-annual-meeting

15th European Molecular Imaging Meeting - EMIM 2020

March 24-27, 2020

Thessaloniki, Greece

www.e-smi.eu/index.php?id=1976

FOM2020 - Focus on Microscopy

April 5-8, 2020

Osaka, Japan

http://focusonmicroscopy.org

Microscopy \& Microanalysis 2020

August 2-6, 2020

Milwaukee, WI

www.microscopy.org

\section{1}

Microscopy \& Microanalysis 2021

August 1-5, 2021

Pittsburgh, PA

www.microscopy.org

\section{2}

Microscopy \& Microanalysis 2022

July 31-August 4, 2022

Portland, OR

www.microscopy.org

Microscopy \& Microanalysis 2023

July 24-28, 2023

Minneapolis, MN

www.microscopy.org

\section{4}

Microscopy \& Microanalysis 2024

July 28-August 1,2024

Cleveland, $\mathrm{OH}$

www.microscopy.org

\title{
A New Organ for Feeling Pain
}

\author{
Stephen W. Carmichael \\ Mayo Clinic, Rochester, MN 55905 \\ carmichael.stephen@mayo.edu
}

Perceiving pain is essential to survival of an organism. One definition of pain is the perception of harmful stimuli. This may be from an internal (inflammation, bowel distention, etc.) or external stimulus (for example, mechanical or thermal), and these types of pain are perceived by nociceptive pain receptors. The current view is that external harmful (noxious) stimuli directly activate unmyelinated nerve endings in the skin. These nerve endings are associated with Remak glial cells that protect and metabolically support the unmyelinated nerves. These Remak glial cells are Schwann cells that do not myelinate the axons. Recently Hind Abdo, Laura Calvo-Enrique, Patrik Ernfors, and others investigated how these cutaneous Remak Schwann cells are distributed and interact with receptors (nociceptive nerve terminals) for detection of noxious stimuli [1]. What they found is described as a distinct type of Schwann cell and a new organ for feeling pain.

Abdo et al. used genetic labeling to identify these cutaneous Schwann cells. Recombination of specifically tagged cells revealed their location in the dermis near the border with the epidermis (Figure 1). Combining this with specific stains for neurons demonstrated that epidermal Schwann cell processes attached to the nerves. Transmission electron microscopy showed that nerve terminals emerged from the soma of Schwann cells located a few micrometers from the border of the epidermis and that the glial cell was the only source of cytoplasmic sheaths for the nerve terminals. These morphologically distinct glia also had other vital characterisitics such as a high expression of aquaporin, a protein that functions in water balance of cells. Nerve and Schwann cell processes were surrounded by a thick layer of fibrillar collagen that was distinct from the rest of the collagen in the dermis. Immunoelectron microscopy further confirmed the existence of a morphologically and molecularly specialized type of Schwann cell that formed a mesh-like network in the subepidermal border. This constituted a glial-neural complex with an intimate association with nociceptive nerves, which is insulated by a structural support of collagen fibers. Abdo et al. called these specialized glial cells nociceptive Schwann cells. These nociceptive cells were found to be a population distinct from other cutaneous Schwann cells.

After the nociceptive Schwann cells were clearly identified, Abdo et al. used a technique called optogenetics to determine if these cells could be stimulated by painful stimuli. Since these cells are located superficially, intense light stimulation was used and was found to elicit limb withdrawal in certain strains of mice. This withdrawal
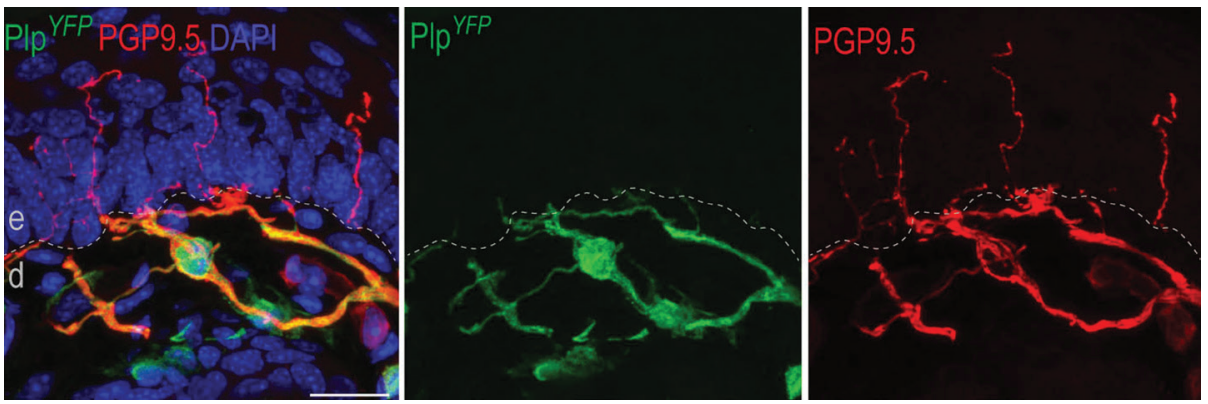

Figure 1: Genetically expressed myelin proteolipid protein, indicated by the marker protein gene product 9.5, and yellow fluorescent protein. Nociceptive Schwann cells in the sub-epidermal border ensheathed unmyelinated nerve endings in mice. Scale bar is $10 \mu \mathrm{m}$. 


\section{A Plasma FIB-SEM platform}

\section{for deep sectioning and the highest}

\section{resolution end-pointing}

\section{for package level failure analysis}

J)

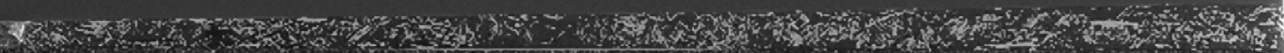

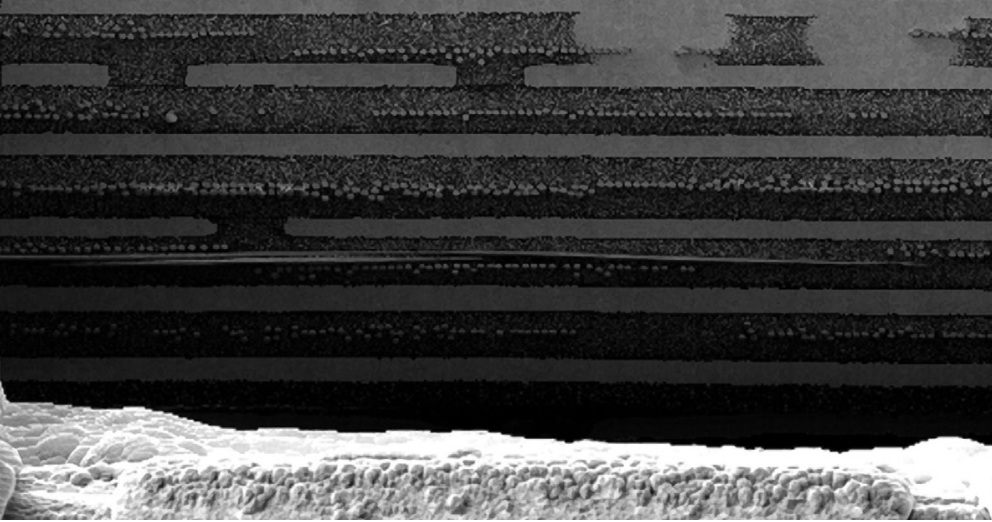

\section{TESCAN SOLARIS X}

$\checkmark$ Curtaining-free large-area cross-sectioning for physical failure analysis of advanced packaging technologies.

$\checkmark$ Prepare large area FIB-cross-sections up to $1 \mathrm{~mm}$ wide.

$\checkmark$ Obtain low noise, high resolution image at low keVs in short acquisition time at FIB-SEM coincidence with the sample tilted.

$\checkmark$ Live SEM-monitoring during FIB milling for precise end-pointing.

$\checkmark$ Observe the most beam-sensitive materials using low keVs ultra-high resolution for surface sensitivity and high material contrast.

$\checkmark$ Effective techniques and recipes for fast and artefact-free cross-sectioning of composite samples (OLED and TFT displays, MEMS devices, isolation dielectrics) at high currents.

$\checkmark$ Essence $^{\text {TM }}$ easy-to-use modular user interface

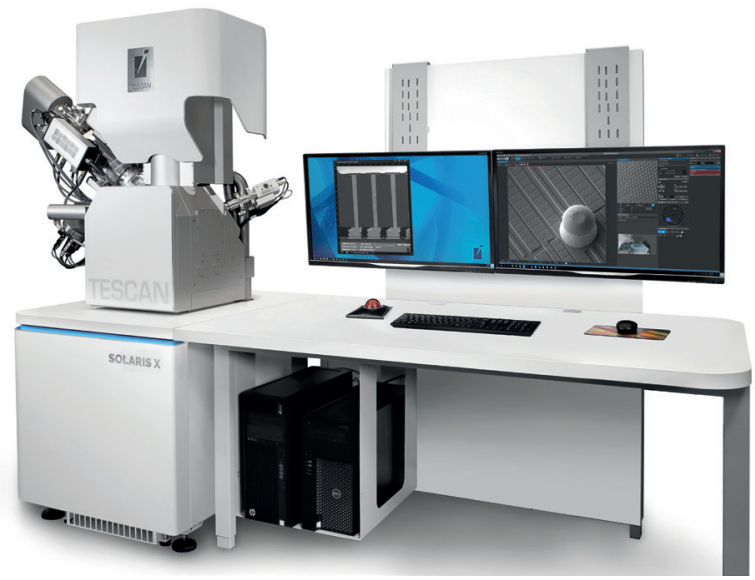

For more information visit 
also elicited shaking and licking of the paw, which are considered to be pain-specific behaviors, and was associated with increased electrical activity in nerves from the paw.

Electrical properties of nociceptive Schwann cells in response to mechanical stimuli were also examined in cultured cells by whole-cell current-clamp electrophysiological recordings. It was found that nociceptive Schwann cells responded to both positive and negative changes in force but much less to sustained force. This and other evidence suggests a very fast response of these cells to mechanical stimuli, similar to what has been described in sensory neurons.

Abdo et al. provide strong evidence for a specialized glial cell type that forms a newly described sensory organ in the skin, responsible for initiating the sensation of pain. The nociceptive Schwann cells and nociceptive nerves form a pain-detecting glial-neural complex with two sensor-receptor cell types: the glia and the nerve. The functional implications of these findings are immense, presenting a new way that animals perceive pain. This is not only important for a better understanding of how the body performs this essential perception of pain, but it could play a key role in developing future therapies for dealing with pain, including treatment of debilitating clinical conditions such as chronic pain syndromes.

\section{References}

[1] Abdo et al., Science 365 (2019) 695-99.

[2] The author gratefully acknowledges Dr. Patrik Ernfors for reviewing this article.
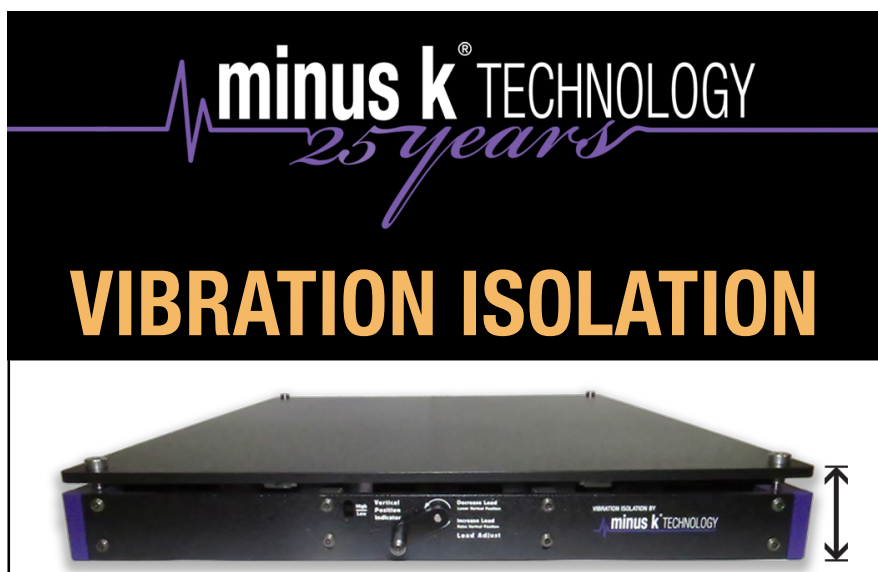

Now only $21 / 4$ inches tall

\section{BREAKTHROUGH}

Ultimate $0.5 \mathrm{~Hz}$ Performance!

Perfect for Milcroscopes

No Air! No Electricity!

sales@minusk.com

www.minusk.com

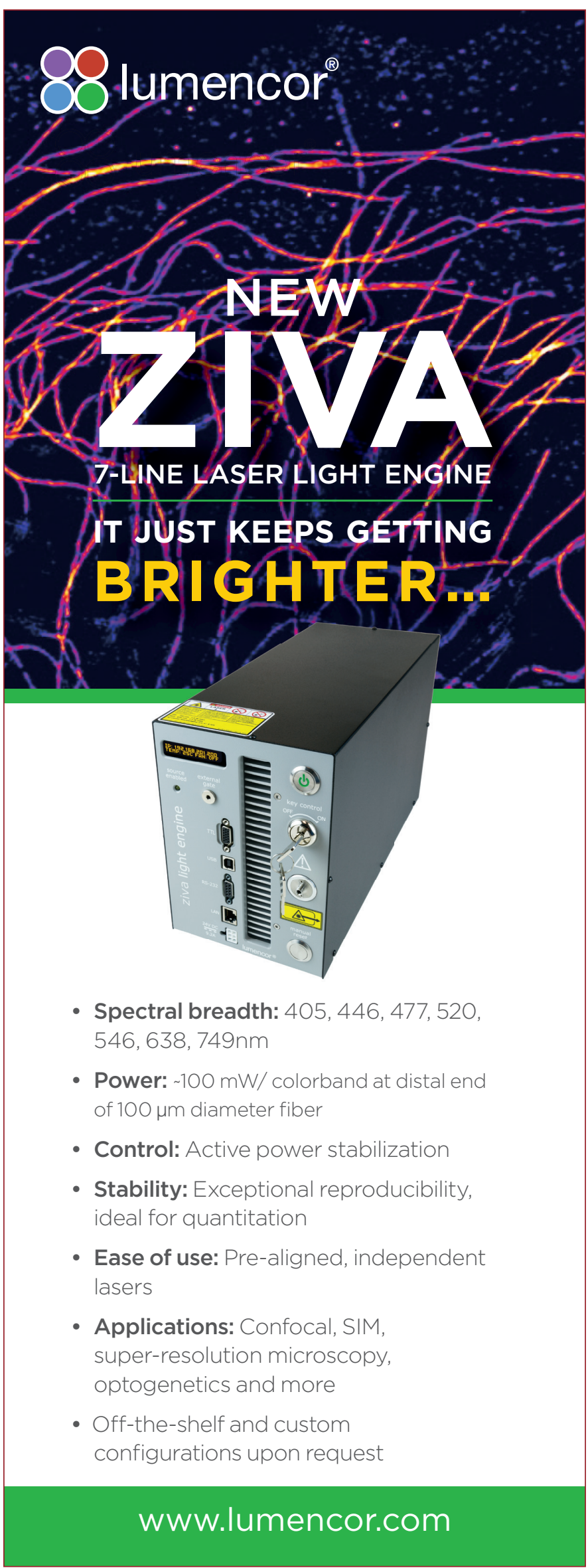

www.microscopy-today.com • 2020 January 
